\title{
ETHNIC DIFFERENCES IN COGNITIVE DEVELOPMENT IN THE FIRST 7 \\ YEARS: DOES MATERNAL GENERATIONAL STATUS MATTER?
}

Neil R. Smith ${ }^{1}$

Yvonne J. Kelly ${ }^{2}$

James Y. Nazroo ${ }^{3}$

\section{Affiliations:}

${ }^{1}$ Centre for Psychiatry, Wolfson Institute of Preventive Medicine, Barts and The London School of Medicine and Dentistry, Queen Mary University of London, EC1M 6BQ

${ }^{2}$ Department of Epidemiology and Public Health, 1-19 Torrington Place, University College London, WC1E 6BT

${ }^{3}$ School of Social Sciences, University of Manchester, Oxford Road, Manchester, M13 9PL

Address correspondence: Centre for Psychiatry, Wolfson Institute of Preventive Medicine, Barts and The London School of Medicine and Dentistry, Charterhouse Square, EC1M 6BQ, UK

E-mail: n.r.smith@qmul.ac.uk

Telephone: +44 2078822039

Manuscript - 3170 words 


\begin{abstract}
Background: Differences in cognitive development have been observed across a variety of ethnic minority groups but relatively little is known about the persistence of these developmental inequalities over time or generations.
\end{abstract}

Methods: A repeat cross sectional analysis assessed cognitive ability scores of children aged three, five and seven years from the longitudinal UK Millennium Cohort Study (White UK born $n=7,630$; Indian $n=248$; Pakistani $n=328$; Bangladeshi $n=87$; Black Caribbean $n=172$; and Black African $n=136$ ). Linear regression estimated ethnic differences in age normed scores at each time point. Multivariable logistic regression estimated within-group generational differences in test scores at each age adjusting stepwise for socio-demographic factors, maternal health behaviours, indicators of the home learning environment and parenting styles.

Results: The majority of ethnic minority groups scored lower than the White UK born reference group at age three with these differences narrowing incrementally at ages five and seven. However the Black Caribbean group scored significantly lower than the White UK born reference group throughout early childhood. At age three, Pakistani, Black Caribbean and Black African children with UK born mothers had significantly higher test scores than those with foreign born mothers after baseline adjustment for maternal age and child gender. Controlling for social, behavioural and parenting factors attenuated this generational advantage. By age seven there were no significant generational differences in baseline models. 
Conclusion: Ethnic differences in cognitive development diminish throughout childhood for the majority of groups. Cumulative exposure to the UK environment may be associated with higher cognitive development scores.

$(248 / 250)$

What is already known on this subject?

- Ethnic differences in cognitive development exist during critical periods of early child development.

What this study adds?

- Ethnic differences in cognitive development narrow between the ages and 3 and 7 for Indian, Bangladeshi, Pakistani and Black African children living in the UK. However, ethnic differences are persistent for Black Caribbean children throughout early childhood.

- Children with UK born mothers score higher on cognitive tests than their counterparts with foreign born mothers but this generational difference diminishes with age.

- Generational differences in cognitive development are partially explained by differences in parental socioeconomic circumstances, behaviours and modifications to the home environment. 


\section{BACKGROUND:}

Ethnic differences in early life development have been described across a range of minority groups within a variety of national contexts ${ }^{12}$. Evidence from the UK suggests that Indian, Black Caribbean and Black African children are less likely to be delayed on developmental milestones at nine months of age, whereas Pakistani and Bangladeshi infants are more likely ${ }^{2}$. At age three, Indian, Pakistani, Bangladeshi, Black African and Black Caribbean children are disadvantaged in terms of cognitive development compared to the White UK population ${ }^{3}$.

Well-established influences on cognitive development include social and economic disadvantage experienced in early childhood ${ }^{4}$. The influence of parental class ${ }^{5}$, education ${ }^{6}$, income ${ }^{7}$, health behaviours (e.g. breastfeeding ${ }^{8}$ ) as well as child care ${ }^{9}$, parenting styles ${ }^{10}$ and household structures ${ }^{11}$ all explain to varying degrees the differences observed between individuals. However, the patterning of exposures shaping cognitive development is not the same across ethnic minority groups. For example, ethnic minority groups in the UK tend to be more socioeconomically disadvantaged than the majority population but the extent of deprivation varies considerably between groups and across socioeconomic indicators ${ }^{12}$. Once such factors are accounted for then there is considerable evidence that ethnic variations in early development are attenuated ${ }^{213}$. Conversely, some ethnic minority groups may be more advantaged than the general population in terms of health behaviours affecting child development. Indian, Pakistani, Bangladeshi and Black Caribbean and Black African mothers in the UK are more likely to breastfeed ${ }^{14}$, and have lower prevalence of smoking in pregnancy ${ }^{15}$ than the general population and have also been observed as being more advantaged on measures of parenting such monitoring, educational involvement and having higher aspirations for their child ${ }^{16}$. Further investigation into the effects of beneficial exposures, such as health promoting behaviours, may have important implications for policies targeting the behaviours of the majority population. 
Most investigations attempting to explain ethnic differences in health have focussed on first generation migrants, or exclude migration status completely. It is important to consider that such social or behavioural factors which may underlie differences in cognitive development are not fixed over time or generation. For instance, some ethnic groups in the UK have been shown to improve upon their occupational social class, obtain higher levels of educational qualifications and experience higher household incomes in the generations following migration ${ }^{17}$. Given that social class is associated with cognition ${ }^{18}$, it is possible that the parents' upward intergenerational social mobility may be accompanied by higher levels of child cognitive development ${ }^{4-7}$. Health and social behaviours might also exert their impact on children's development via biological pathways (e.g. lipid or growth hormone content of breast milk ${ }^{19}$ ), or psychosocial pathways (e.g interactions between parents and children ${ }^{7}$ ), or a combination of pathways. Yet the behaviours underpinning these pathways to development are liable to change as a consequence of acculturation and approximation towards the social norms of the majority population ${ }^{2021}$. It is therefore likely that significant generational differences in development exist in ethnic minority children, but these patterns and the underlying casual pathways have been neglected in the research to date.

The overall aim of this study is to describe generational differences in ethnic inequalities in cognitive development over the first seven years of life and identify factors determining these differences. The first objective is to examine the extent to which socio-demographic characteristics differ between generations. The second objective identifies generational differences in the home learning environment and parent styles. Further investigation will examine whether there are ethnic differences in child cognitive development at ages three, five and seven (objective 3). The final objective estimates the magnitude of generational differences in development and assesses the influence of purported socio-demographic and environmental causal factors (objective 4). The investigation hypothesises that cross- 
generational differences in development are accounted for by differences in socioeconomic disadvantage, as well as variations in parenting styles and the home learning environment.

\section{METHODS}

The Millennium Cohort Study (MCS) is a nationally representative longitudinal study of 19244 families with children born in the United Kingdom (UK) between 2000 and $2002{ }^{22}$. This investigation uses family interviews and child assessments conducted for all participants at ages three, five and seven years. The family interview was completed by the main carer of the cohort member at each time point.

\section{Ethnicity}

Child's ethnicity was defined by a parent using categories from the 2011 England and Wales Census ${ }^{23}$. The five largest non-mixed ethnic minority groups living in the UK were eligible for analysis: Indian, Pakistani, Bangladeshi, Black Caribbean and Black African. The mixed group was excluded due to considerable heterogeneity in terms of family origins as well as socioeconomic characteristics.

\section{Generation}

Child generational status was defined according mother's nativity. When assessing child outcomes the "UK Born" category refers to a child with a UK born mother whereas "Foreign Born" implies the mother was born overseas. Comparing generations living in the same time period mitigates against unknown contextual effects which may confound comparisons between generations living consecutively.

\section{Cognitive development}


All cognitive tests were interviewer-administered in the home. At age three, children completed the Bracken School Readiness Assessment (BSRA) which measures the comprehension of 88 concepts relating to colours, letters, numbers, sizes, comparisons and shapes to predict readiness for more formal education ${ }^{24}$. In addition, the naming vocabulary component from the British Abilities Scales (BAS) ${ }^{25}$ asked children to name items from a booklet of coloured objects. At age five, the BAS naming vocabulary test was repeated. The naming vocabulary test was repeated in addition to the pattern construction battery. This tested spatial awareness, dexterity and coordination whereby the child constructs a design from patterned squares and cubes. A third picture similarity component assessed problem solving by asking the child to place pictures alongside matching pairs. At age seven, the BAS word reading assessment was administered to measure children's reading ability. Number skills were assessed using the standard Progress in Maths test ${ }^{26}$, and the BAS pattern construction test was re-administered.

Each cognitive test score was age-normed against its respective reference population ${ }^{27}$ and was transformed to a z-score to allow subscale comparisons. Principal components analysis (PCA) has been previously used on this data to derive a weighted index score which quantifies a unifying general characteristic ${ }^{28}{ }^{29}$. The combined index score captured the maximum possible variation between the scores and was normalised to mean zero and unit variance. The index captured $70 \%, 58 \%$ and $57 \%$ of the variation between ability scores at ages three, five and seven respectively. All items within each index were positively correlated with one another and made roughly equal contributions to the combined index.

\section{Explanatory factors}

Demographic factors included the mother's age at birth and household language at each time point (English only; mostly English; mostly another language). Socioeconomic factors were 
assigned at age three and included the parents' highest current or previous occupational social class using the National Statistics Socioeconomic Classification (NS-SEC). This schema was collapsed into a three tier hierarchical scale ${ }^{30}$, with an additional category for parents who had never held a job. The parents' highest qualification was summarised on a four tier hierarchical scale, with an additional category for overseas qualifications. Maternal health behaviours included whether the mother smoked in pregnancy and whether the child was ever breastfed. The child's home learning environment was assessed using age-specific measures

${ }^{31}$. Age three assessed how often the child was read to, and how frequently they were helped with the alphabet, taught songs or rhymes, painted at home and taught to count by the parent. Age five assessed how frequently the child was read to, attended a library, taught songs or stories, painted at home and played with toys with a parent. Age seven assessed how frequently the child was helped with reading, writing and maths. Home learning responses for each age were collapsed to a summary score and split into quintiles. Lastly, parenting style was assessed at each age according to whether the family has rules, whether they are enforced, does the child have regular mealtimes and bedtimes, and how many hours per day the child watches television.

\section{Statistical analysis}

This complete case analysis of 8,601 singleton births uses a repeat cross section of the same individuals at all three time points. Analyses were conducted using Stata SE, Version 13.1 (Stata Corporation, Texas, USA) and used survey weights to account for the clustered sampling design. Foreign born White UK mothers were excluded in order to describe the extent of ethnic inequalities relative to the majority of the population who are UK born. Descriptive analyses show the generational differences in the distribution of demographic, socioeconomic and health behavioural factors as well as indicators of the home learning environment and parenting styles at age three. A repeat cross sectional analysis was 
performed to examine whether the size of the relative differences in development varied by age. Linear regression estimated the difference in the age and gender standardised mean cognitive development z-score between ethnic minority groups and the White UK born reference group at ages three, five and seven respectively. Lastly, multivariable linear regression estimated differences in the mean z-score between children with foreign born mothers and those with UK born mothers for each ethnic group, by age. Models were adjusted stepwise for socio-demographic factors, maternal health behaviours, the home learning environment and parenting styles.

\section{Missing data}

Missing data was highest for test scores at age 3 (11.5\%) due to a lack of parental consent. Missing data averaged 3.6\% across all other variables. A sensitivity analysis was performed using multiply imputed data derived using a burn in of 20,000 iterations to stabilise the Markov chains. A further 25,000 iterations were run creating 50 imputed datasets at every 500th iteration. There was little variation in mean $\mathrm{z}$ scores between the complete case and imputed data. Longitudinal weights were also applied to account for non-response and minimise bias due to loss to follow-up.

\section{RESULTS}

Table 1 shows a greater proportion of households with foreign born mothers were disadvantaged than their UK born counterparts in terms of social class, and to a lesser extent for education. Overall, the prevalence of smoking in pregnancy was considerably higher in the UK born mothers than the foreign born for all ethnic minority groups. Lastly, there were inconsistent generational differences in the initiation of breastfeeding. The proportion of Indian and Black Caribbean mothers who never breastfed was higher for those who were UK 
born, whereas the proportion was higher for foreign born Pakistani, Bangladeshi and Black African mothers. 
Table 1: Maternal and parental demographic, socioeconomic and health behavioural characteristics of MCS sample present at child's age 3 by generation and ethnic group (weighted percentages given; $n=$ unweighted number of observations; significantly different to White UK born reference)

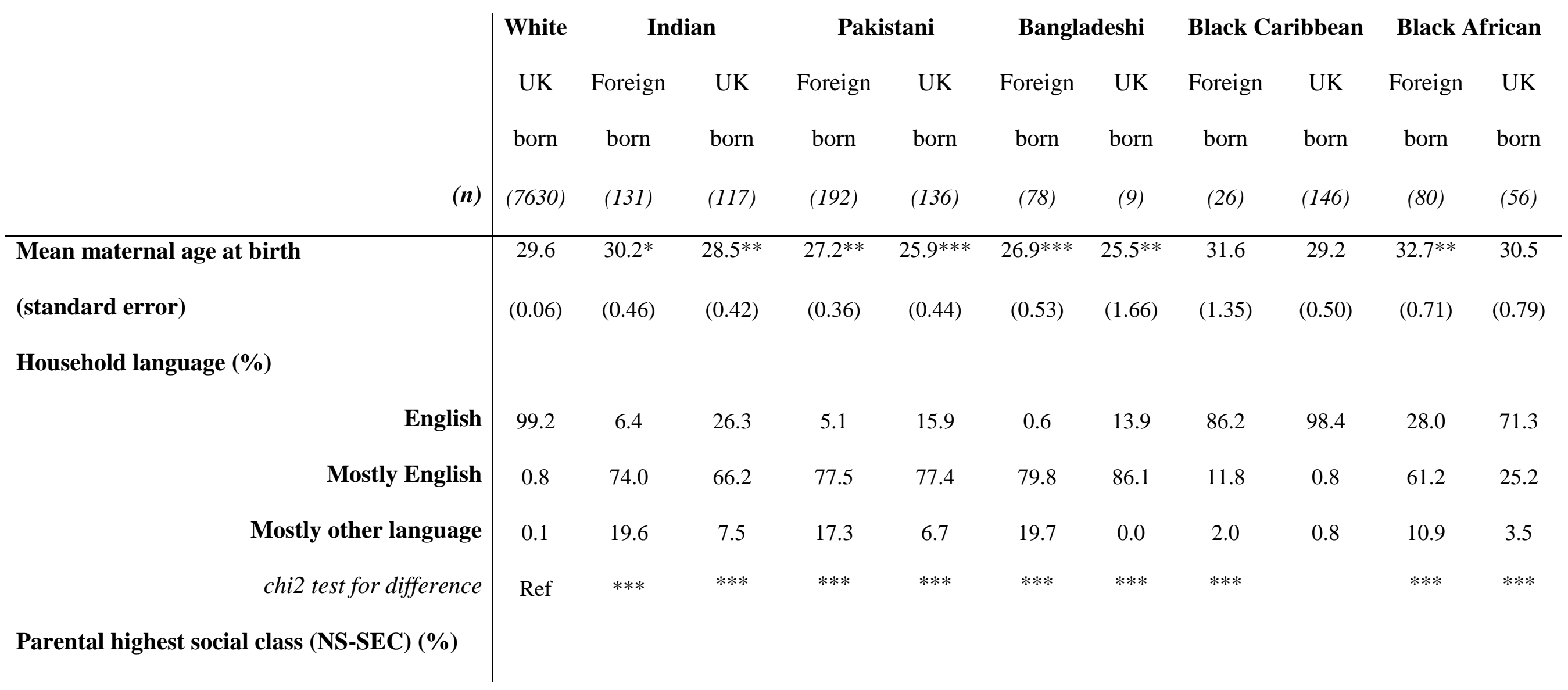




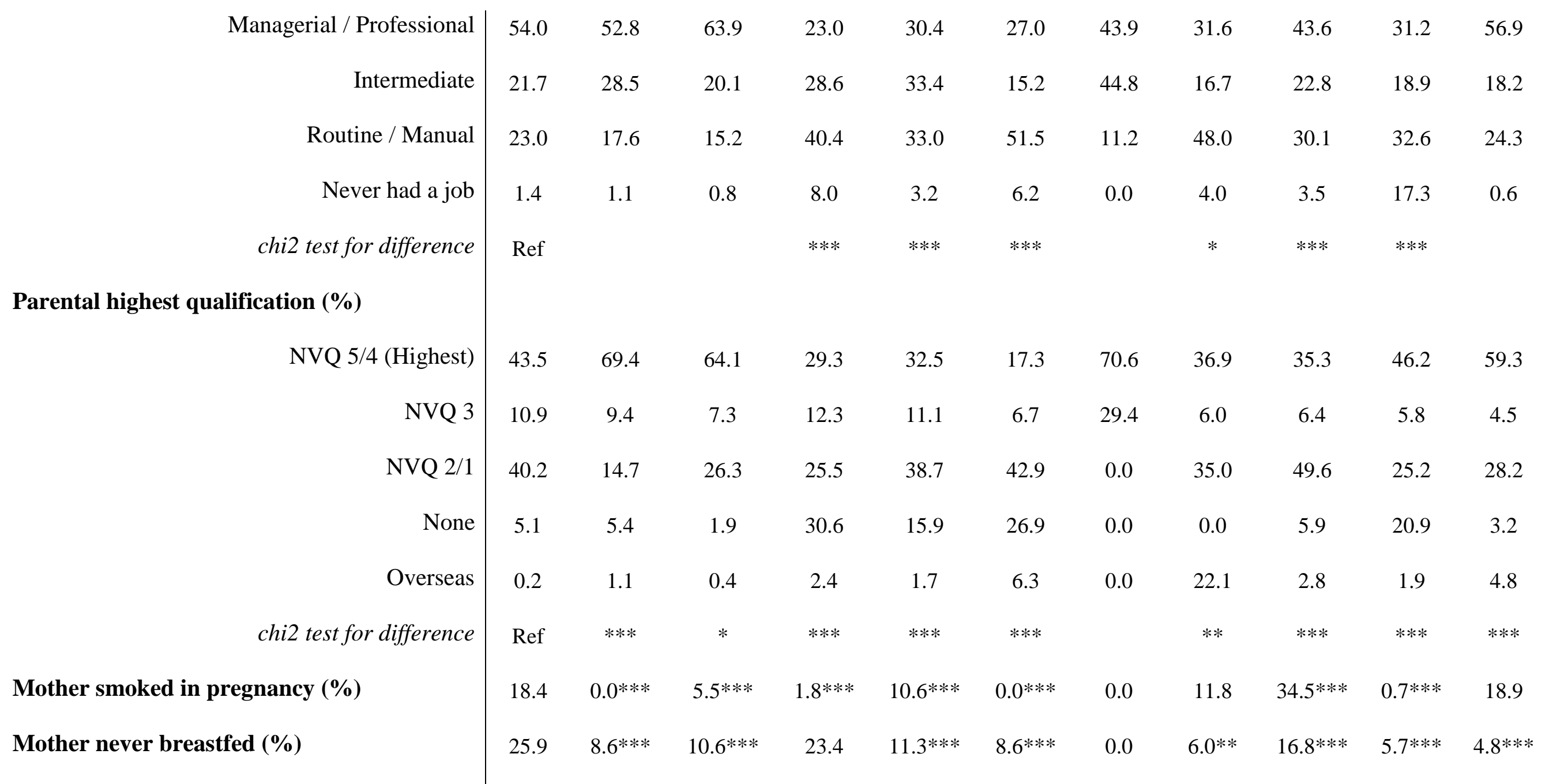

Parental highest qualification (\%)

Notes: * significantly different to White UK born reference: $* \mathrm{p}<0.05 ; * * \mathrm{p}<0.01 ; * * * \mathrm{p}<0.001$ 
For brevity, table 2 presents the proportion of parents reporting learning practices most frequently or who reported disciplined parenting behaviours. Families with foreign born mothers were more likely to have a home learning environment score in the lowest quintile, with exception of the Pakistani group. Compared to White UK born, Pakistani children with foreign and UK born mothers, and children with foreign born born Bangladeshi and Black African mothers were significantly more likely to be in the lowest quintile. Collapsing parenting styles to a summary score at age three resulted in a low alpha coefficient $(\alpha=0.44)$, so behaviours were assessed individually at each age. For the majority of behaviours, parental control tended to be higher or enforced in households with UK born mothers. Overall, these data demonstrate that there are associations between ethnic groups, generation and the home environment and sociodemographic factors which ought to be accounted for in final explanatory models. 
Table 2: Generational differences in the home learning environment (HLE) and parenting styles at age 3 (weighted percentages given; $n=$ unweighted number of observations)

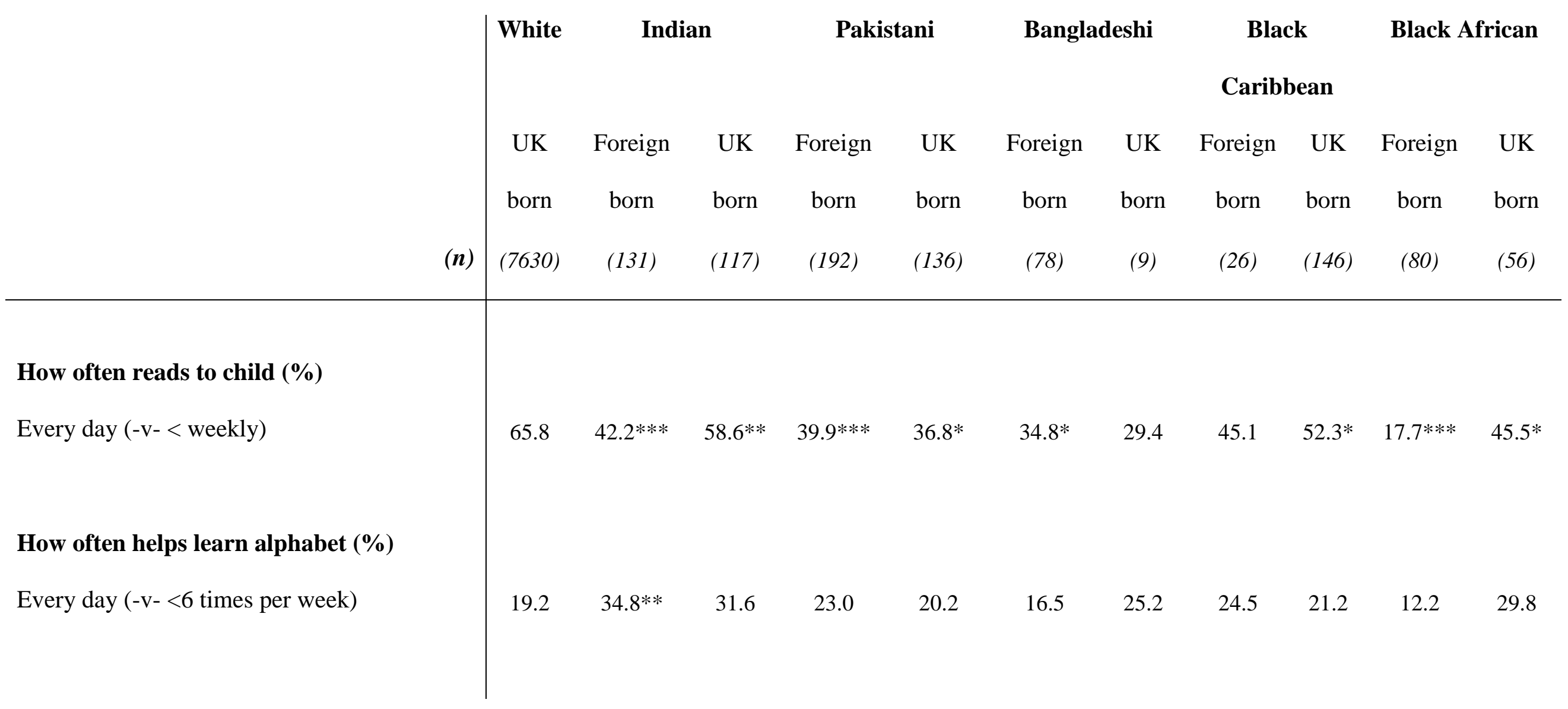


How often teaches child songs/rhymes (\%)

Every day (-v- $<6$ times per week)

How often child paints/draws at home (\%)

Every day (-v- $<6$ times per week)

How often teach child to count (\%)

Every day (-v- $<6$ times per week)

\section{Overall HLE Score (\%)}

Lowest quintile (poorest environment)

\section{Household has rules (\%)}

Lots of rules (-v- not many rules or varies)

Whether rules are enforced (\%)
57.2

53.9

$57.2^{* *}$

40.4

41.9

43.9

30.2

25.2

48.0

39.7

49.8

47.3

51.9

55.3

46.7

41.0

39.1

$24.0^{* *}$

47.6

36.3

46

$30.9^{*}$

59.2

22.4

28.1

25.8

$40.8^{* * *}$

$43.3^{* * *}$

$53.7^{* * *}$

48.4

33.3

22.0

$55.4 * * *$

24.7

31.8

28.2

$16.0^{* * * *}$

$22.2^{*}$

17.9

59.4*

36.1

37.8

36.8

30.6 
Strictly enforced (-v- not strict or varies)

Whether child has regular bedtimes (\%)

Always (-v- usually/sometimes/never)

Whether child has regular mealtimes (\%)

Always (-v- usually/sometimes/never)

Hours of TV watched per day (\%)

Less than one (-v- more than one)
51.8

40.5

52.2

$20.6^{* *}$

$31.6 * * *$

37.0

$22.4^{*}$

29.6

57.8

43.7

46.7 
Differences in age standardised cognitive test $\mathrm{z}$ scores between ethnic minority groups and the UK born White reference population are shown by age in table 3 . A negative value suggests a lower score than the White UK born group. There were significant ethnic inequalities in development in all groups at age three as all ethnic minority groups scored significantly lower than the White UK born reference group. Importantly, the differences compared to the White UK born group steadily diminished with increasing age. This was to the extent that Indian ( $\beta: 0.21$, 95\% CI [-0.01,0.44]), Bangladeshi (-0.32 [-0.71,0.07]) and Black African (-0.13 [-0.40,0.13]) children had scores comparable to White UK born children by age seven. A notable exception was observed for Black Caribbean children. Although Black Caribbean children narrowed the gap with the White UK born reference between the ages of three and five, the differential widened between ages five and seven.

Table 3: Difference in age standardised mean z-scores compared to the White UK born group at ages 3, 5 and 7, by ethnicity (regression coefficients for difference and $95 \%$ confidence intervals shown)

\begin{tabular}{l|ccl} 
& \multicolumn{1}{|c}{ Age 3 } & Age 5 & \multicolumn{1}{c}{ Age 7 } \\
\hline Indian & $-0.38^{*}[-0.68,-0.08]$ & $-0.25^{* *}[-0.42,-0.09]$ & $0.21[-0.01,0.44]$ \\
Pakistani & $-1.57^{* * *}[-1.82,-1.32]$ & $-1.07 * * *[-1.30,-0.85]$ & $-0.46^{* *}[-0.74,-0.17]$ \\
Bangladeshi & $-2.03^{* * *}[-2.27,-1.80]$ & $-1.07 * * *[-1.34,-0.81]$ & $-0.32[-0.71,0.07]$ \\
Black Caribbean & $-0.50^{* * *}[-0.75,-0.26]$ & $-0.32 * *[-0.52,-0.12]$ & $-0.56 * * *[-0.85,-0.26]$ \\
Black African & $-0.68^{* * *}[-0.91,-0.44]$ & $-0.59^{* * *}[-0.82,-0.36]$ & $-0.13[-0.40,0.13]$ \\
\hline
\end{tabular}

Notes: adjusted for child's gender; (significantly different to White UK born: * $\mathrm{p}<0.05,{ }^{* *} \mathrm{p}<0.01$, $* * * \mathrm{p}<0.001)$ 
A direct estimate of the difference in cognitive development scores between children with foreign and UK born mothers was derived and adjusted stepwise for potential explanatory factors. These generational differences were estimated for all groups at age ages three, five and seven respectively (Table 4). A positive regression coefficient represents a higher z-score in children with UK born mothers compared to those with foreign born. At age three, Pakistani ( $\beta$ : $0.38,95 \%$ CI $[0.02,0.73])$, Black Caribbean $(0.84[0.14,1.54])$ and Black African $(0.90$ $[0.45,1.35])$ children with UK born mothers had significantly higher test scores than those with foreign born mothers. Stepwise adjustment for household language (Model 2), socioeconomic factors (Model 3) maternal health behaviours (Model 4) and home learning environments and parenting styles (Model 5) accounted for an incremental reduction in the generational gap in most ethnic minority groups. However, after full adjustment, Bangladeshi children with UK born mothers were significantly more likely to have higher scores than those with foreign born mothers though this is interpreted cautiously based on the low UK born sample size. At age five Black African and Pakistani children with UK born mothers again scored significantly higher than children with foreign born mothers but this was not significant after full adjustment. By age seven these there were no significant generational differences in any models with exception to the small Bangladeshi sample. 
Table 4: Generational difference in age standardised mean z-scores, adjusting stepwise for demographic and socioeconomic factors, maternal health behaviours, and the home learning environment and parenting style (regression coefficients for difference and $95 \%$ confidence intervals shown).

\begin{tabular}{|c|c|c|c|c|c|}
\hline & Model 1 & Model 2 & Model 3 & Model 4 & Model 5 \\
\hline \multicolumn{6}{|l|}{ AGE 3} \\
\hline \multirow[t]{2}{*}{ Indian } & 0.30 & 0.16 & 0.14 & 0.14 & 0.04 \\
\hline & {$[-0.19,0.78]$} & {$[-0.26,0.58]$} & {$[-0.30,0.57]$} & {$[-0.30,0.59]$} & {$[-0.32,0.39]$} \\
\hline \multirow[t]{2}{*}{ Pakistani } & $0.38^{*}$ & 0.17 & 0.03 & -0.02 & 0.00 \\
\hline & {$[0.02,0.73]$} & {$[-0.16,0.51]$} & {$[-0.29,0.34]$} & {$[-0.34,0.30]$} & {$[-0.26,0.25]$} \\
\hline \multirow[t]{2}{*}{ Bangladeshi } & 0.29 & 0.16 & 0.24 & 0.17 & $0.51^{*}$ \\
\hline & {$[-0.26,0.84]$} & {$[-0.38,0.71]$} & {$[-0.33,0.80]$} & {$[-0.43,0.77]$} & {$[0.09,0.94]$} \\
\hline \multirow[t]{2}{*}{ Black Caribbean } & $0.84^{*}$ & $0.77^{*}$ & 0.65 & 0.56 & 0.27 \\
\hline & {$[0.14,1.54]$} & {$[0.03,1.51]$} & {$[-0.01,1.31]$} & {$[-0.11,1.24]$} & {$[-0.30,0.83]$} \\
\hline \multirow[t]{2}{*}{ Black African } & $0.90^{* * * *}$ & $0.61^{*}$ & 0.24 & 0.34 & 0.13 \\
\hline & {$[0.45,1.35]$} & {$[0.13,1.10]$} & {$[-0.21,0.68]$} & {$[-0.12,0.80]$} & {$[-0.36,0.62]$} \\
\hline \multicolumn{6}{|l|}{ AGE 5} \\
\hline \multirow[t]{2}{*}{ Indian } & 0.32 & 0.25 & 0.24 & 0.22 & 0.23 \\
\hline & {$[-0.05,0.68]$} & {$[-0.12,0.61]$} & {$[-0.12,0.61]$} & {$[-0.15,0.59]$} & {$[-0.11,0.56]$} \\
\hline Pakistani & $0.40^{*}$ & 0.23 & 0.10 & 0.04 & 0.02 \\
\hline
\end{tabular}




\begin{tabular}{|c|c|c|c|c|c|}
\hline & {$[0.08,0.72]$} & {$[-0.09,0.54]$} & {$[-0.23,0.42]$} & {$[-0.28,0.36]$} & {$[-0.28,0.32]$} \\
\hline \multirow[t]{2}{*}{ Bangladeshi } & 0.18 & 0.17 & 0.43 & $0.54 *$ & 0.59 \\
\hline & {$[-0.17,0.52]$} & {$[-0.25,0.60]$} & {$[-0.07,0.94]$} & {$[0.03,1.05]$} & {$[-0.21,1.39]$} \\
\hline \multirow[t]{2}{*}{ Black Caribbean } & 0.24 & 0.21 & 0.22 & 0.26 & 0.11 \\
\hline & {$[-0.23,0.71]$} & {$[-0.29,0.71]$} & {$[-0.30,0.75]$} & {$[-0.30,0.83]$} & {$[-0.41,0.63]$} \\
\hline \multirow[t]{2}{*}{ Black African } & $0.47^{*}$ & 0.26 & -0.08 & -0.03 & -0.12 \\
\hline & {$[0.05,0.90]$} & {$[-0.19,0.71]$} & {$[-0.49,0.33]$} & {$[-0.46,0.40]$} & {$[-0.61,0.38]$} \\
\hline \multicolumn{6}{|c|}{ AGE 7} \\
\hline \multirow[t]{2}{*}{ Indian } & 0.12 & 0.03 & 0.01 & -0.02 & -0.12 \\
\hline & {$[-0.26,0.51]$} & {$[-0.35,0.42]$} & {$[-0.40,0.42]$} & {$[-0.43,0.39]$} & {$[-0.51,0.27]$} \\
\hline \multirow[t]{2}{*}{ Pakistani } & 0.33 & 0.24 & 0.05 & 0.02 & -0.04 \\
\hline & {$[-0.09,0.75]$} & {$[-0.20,0.68]$} & {$[-0.36,0.46]$} & {$[-0.40,0.43]$} & {$[-0.43,0.34]$} \\
\hline \multirow[t]{2}{*}{ Bangladeshi } & -0.18 & -0.23 & -0.74 & -0.65 & -0.85 \\
\hline & {$[-0.82,0.45]$} & {$[-1.01,0.55]$} & {$[-1.48,0.01]$} & {$[-1.42,0.11]$} & {$[-1.79,0.09]$} \\
\hline \multirow[t]{2}{*}{ Black Caribbean } & 0.75 & 0.67 & 0.65 & 0.64 & 0.63 \\
\hline & {$[-0.22,1.71]$} & {$[-0.39,1.73]$} & {$[-0.35,1.66]$} & {$[-0.34,1.62]$} & {$[-0.18,1.43]$} \\
\hline \multirow[t]{2}{*}{ Black African } & 0.24 & 0.09 & -0.28 & -0.01 & -0.21 \\
\hline & {$[-0.34,0.82]$} & {$[-0.50,0.68]$} & {$[-0.92,0.36]$} & {$[-0.64,0.63]$} & {$[-0.72,0.31]$} \\
\hline
\end{tabular}

Notes: $* \mathrm{p}<0.05, * * \mathrm{p}<0.01, * * * \mathrm{p}<0.001$

Coefficient represents the difference in age standardised mean z score in the UK born generation compared to the foreign born. Positive value=UK born higher scoring 
Model 1: Adjusts maternal age at birth and child gender

Model 2: Adjusts for Model $1+$ age-specific household language

Model 3: Adjusts for Model $2+$ age-specific parental socioeconomic characteristics

Model 4: Adjusts for Model 3 + maternal health related behaviours

Model 5: Adjusts for Model 4 + age-specific home learning environment + parenting style

\section{DISCUSSION}

Ethnic minority children had significantly lower cognitive development test scores than White UK born children at age three. It appears that these children "catch-up" with White UK born children by age five, and two years after school entry ethnic differences were considerably diminished for all but the Black Caribbean children. The extent of these developmental differences varied according to the generational status of the mother. Children with UK born mothers scored higher for cognitive development than those with foreign born mothers though this was not significant in many cases due to limited power. This advantage diminished after differences in the distribution of the parental socio-demographic, economic and home learning environments, maternal health behaviours and parenting styles were controlled for. Therefore generational inequalities in early life cognitive development do exist within ethnic minority children, yet these inequalities appear amenable to change. These findings highlight the importance of changing social experiences of individual ethnic groups across time and the extent to which they may explain developmental outcomes which are known to predict later life health $^{32}$.

This study indirectly showed that generational differences in development narrow over time as there were no observable differences apparent by age seven. A cumulative exposure to the UK 
following migration has been shown to result in acculturative changes which may influence behaviours and ultimately health ${ }^{1521}$. It is possible that the developmental scores of children with foreign born mothers may have increased to a greater degree throughout childhood than in those with UK born mothers, due to the greater scope for acculturative change. Indeed, data presented describe a limited degree of approximation across generations in home learning behaviours and parenting styles towards to those practised by the (higher scoring) White UK reference group. Cross-generational uptake of these behaviours might also explain why ethnic minority children with UK born mothers scored more highly overall than those with foreign born mothers.

As well as behavioural explanations there was an implied association between socioeconomic advantage in all UK born groups and higher cognitive test scores. In the majority of groups the generational differences in test scores were attenuated slightly after controlling for this advantage, at all ages. These findings are supported by previous work with the MCS using alternative markers of social circumstances ${ }^{23}$, as well as investigations from elsewhere ${ }^{110}$. These findings continue to suggest that reducing socioeconomic disadvantage in early life is likely to have a positive impact in reducing health inequalities in early years as well as over the remainder of the life course.

Throughout early childhood the significant and persistent inequality observed in Black Caribbean children contrasted significantly to the other ethnic minority groups, despite the Black Caribbean group being relatively more advantaged in terms of parental social class and qualifications. Lower educational achievement by Black Caribbean males in particular has been a matter of contested debate in the UK for over forty years ${ }^{33}$. Racism-led explanations, such as teachers having low expectations based on stereotypes ${ }^{34}$, or cultural explanations whereby 
educational success is not viewed by the child as desirous ${ }^{35}$, have been presented as likely mechanisms influencing development. There is further evidence that mothers' experienced racism is linked to markers of early child development ${ }^{36}$, with Garcia Coll and colleagues suggesting that racism leads to segregated contexts which may influence developmental process in children ${ }^{37}$. Alternatively, our findings may be a consequence of the recognised cultural limitations of the BAS ${ }^{2538}$, and groups with lower levels of English proficiency may be disadvantaged in completing verbal tests. To account for this, household language was taken into account in our models. Yet the Black Caribbean group had the greatest proportion of homes speaking English suggesting that language issues are an unlikely source of significant bias in this scenario. Nevertheless, despite accounting for differences in parenting values and beliefs, and language biases, this study could not confirm why the test scores of only the Black Caribbean children did not converge to those of the White UK majority population..

\section{Strengths and Limitations}

These findings from a large nationally representative longitudinal study are consistent with other studies which were limited by shorter follow-up periods ${ }^{13}$. The findings from the Black Caribbean group are similar to American studies describing persistently lower test scores for Black children into later childhood ${ }^{39}$. Although modelling produced broadly consistent trends across most groups, many values did not reach statistical significance. This was due to restricted sample sizes, particularly so for the Bangladeshi group for which results should be interpreted cautiously despite many of the observed trends being broadly similar to those of other minority groups. Relatedly, larger models controlling for ethnic differences in physical activity, dietary habits and body composition and child care, which may be associated with cognitive development, were not possible due to the limited power within the highly stratified sample. 
Developmental differences between children attending state or private schools were controlled for, but were not significant in final models and are not shown. Finally, foreign born mothers' indicators of socioeconomic position may not be an accurate reflection of lifetime social position due to downward social mobility following migration ${ }^{40}$.

\section{CONCLUSION}

For the majority of ethnic minority groups, inequalities in cognitive development appear to consistently narrow throughout early childhood. However, children of all groups with UK born mothers score higher in cognitive tests, suggesting that intergenerational exposure to the UK social environment may have a positive influence on development.

Abbreviations: SES - socioeconomic status; HLE - Home learning environment; OR - odds ratio; CI - confidence interval; MCS - Millennium Cohort Study; NS-SEC - National Statistics Socioeconomic Classification

Funding Source: The Millennium Cohort Study is funded by the Economic and Social Research Council and a consortium of UK Government departments and is carried out by the Centre for Longitudinal Studies at the Institute for Education, London. This work was supported by a joint Economic and Social Research Council/Medical Research Council interdisciplinary studentship [PTA-037-2006-00059 to NRS]

Financial Disclosure: None required 
Conflict of Interest: None

Clinical Trial Registration: Not applicable

Ethical Approval: Approval for the Millennium Cohort Study was granted at ages three (MREC/03/2/022) and five (05/MRE02/46) by the London Multi-centre Research Ethics

Committee of the NHS. Approval was obtained at age seven from the Northern \& Yorkshire Multi-centre Research Ethics Committee of the NHS (07/MRE03/32). 


\section{REFERENCES}

1. Brooks-Gunn J, Klebanov PK, Duncan GJ. Ethnic differences in children's intelligence test scores:

Role of economic deprivation, home environment, and maternal characteristics. Child development 1996;67(2):396-408.

2. Kelly Y, Sacker A, Schoon I, et al. Ethnic differences in achievement of developmental milestones by 9 months of age: the Millennium Cohort Study. Developmental Medicine and Child Neurology 2006;48(10):825-30.

3. Dearden L, Sibieta L. Ethnic inequalities in child outcomes. Children of the 21 st Century - The First Five Years. Bristol: The Policy Press, 2010:169-84.

4. Brooks-Gunn J, Duncan GJ. The effects of poverty on children. The future of children 1997:55-71.

5. Feinstein L. Inequality in the Early Cognitive Development of British Children in the 1970 Cohort. Economica 2003;70:73-97.

6. Carneiro P, Meghir C, Parey M. Maternal education, home environments, and the development of children and adolescents. Journal of the European Economic Association 2013;11:123-60.

7. Kelly Y, Sacker A, Del Bono E, et al. What role for the home learning environment and parenting in reducing the socioeconomic gradient in child development? Findings from the Millennium Cohort Study. Archives of Disease in Childhood 2011;96(9):832-37.

8. Anderson JW, Johnstone BM, Remley DT. Breast-feeding and cognitive development: a meta-analysis. The American Journal of Clinical Nutrition 1999;70(4):525-35.

9. Peisner-Feinberg ES, Burchinal MR, Clifford RM, et al. The Relation of Preschool Child-Care Quality to Children's Cognitive and Social Developmental Trajectories through Second Grade. Child development 2001;72(5):1534-53.

10. McLoyd VC. Socioeconomic disadvantage and child development. American psychologist 1998;53(2):185. 
11. Evans GW, Ricciuti HN, Hope S, et al. Crowding and Cognitive Development: The Mediating Role of Maternal Responsiveness Among 36-Month-Old Children. Environment and Behavior 2010;42(1):135-48.

12. Nazroo JY. Genetic, cultural or socio-economic vulnerability? Explaining ethnic inequalities in health. Sociology of Health \& Illness 1998;20(5):710-30.

13. Kelly Y, Panico L, Bartley M, et al. Why does birthweight vary among ethnic groups in the UK? Findings from the Millennium Cohort Study. Journal of Public Health 2009;31(1):131-37.

14. Kelly YJ, Watt RG, Nazroo JY. Racial/ethnic differences in breastfeeding initiation and continuation in the United Kingdom and comparison with findings in the United States. Pediatrics 2006;118(5):E1428-E35.

15. Hawkins SS, Lamb K, Cole TJ, et al. Influence of moving to the UK on maternal health behaviours: prospective cohort study. BMJ 2008;336:1052-55.

16. Strand S. The limits of social class in explaining ethnic gaps in educational attainment. British Educational Research Journal 2011;37(2):197-229.

17. Smith NR, Kelly YJ, Nazroo JY. Intergenerational continuities of ethnic inequalities in general health in England. Journal of Epidemiology and Community Health 2009;63(3):253-58.

18. Jefferis BJMH, Power C, Hertzman C. Birth weight, childhood socioeconomic environment, and cognitive development in the 1958 British birth cohort study. British Medical Journal 2002;325(7359):305-08.

19. Quigley MA, Hockley C, Carson C, et al. Breastfeeding is associated with improved child cognitive development: a population-based cohort study. The Journal of pediatrics 2012;160(1):25-32.

20. Salant T, Lauderdale DS. Measuring culture: a critical review of acculturation and health in Asian immigrant populations. Social Science \& Medicine 2003;57(1):71-90.

21. Smith NR, Kelly YJ, Nazroo JY. The effects of acculturation on obesity rates in ethnic minorities in England: evidence from the Health Survey for England. EurJPublic Health 2012;22(4):508-13. 
22. Plewis I. Millennium Cohort study: Technical Report on Sampling, 4th Edition. London: Institute of Education, University of London 2007.

23. Office for National Statistics. Office for National Statistics: 2011 Census Questionnaire Content for England. http://wwwonsgovuk/ons/guide-method/census/2011/the-2011-census/2011-censusquestionnaire-content/2011-census-questionnaire-for-englandpdf 2011. http://www.ons.gov.uk/ons/guide-method/census/2011/the-2011-census/2011-censusquestionnaire-content/2011-census-questions---england.pdf (accessed 02/04/2015).

24. Hansen K. Millennium Cohort Study: A guide to the datasets (8th ed.). 2014. http://www.cls.ioe.ac.uk/shared/get-file.ashx?id=1847\&itemtype=document (accessed 02/04/2015).

25. Elliott CD, Smith P, McCulloch K. British Ability Scales II : technical manual. 2nd ed. ed: London : NFER - Nelson,, 1997.

26. Fernandes CM. CAT4 Cognitive Abilities Test (4th ed.). 2004. http://www.glassessment.co.uk/products/cat4-cognitive-abilities-test-fourth-edition (accessed 02/04/2015).

27. Elliott CD, Smith P, McCulloch K. British Ability Scales II : Administration and Scoring Manual. 2nd ed. ed: London : NFER - Nelson,, 1996.

28. Jones ES, I. Millennium Cohort Study Third Survey: A user's guide to initial findings. 2008. http://www.cls.ioe.ac.uk/shared/get-file.ashx?id=312\&itemtype=document (accessed 04/09/2015).

29. Washbrook E. Early environments and child outcomes: an analysis commission for the Independent Review on Poverty and Life Chances. Centre for Market and Public Organization, University of Bristol 2010.

30. Rose D, Pevalin DJ. The National Statistics socio-economic classification : unifying official and sociological approaches to the conceptualisation and measurement of social class: Colchester : Institute for Social and Economic Research, University of Essex,, 2001. 
31. Melhuish EC, Phan MB, Sylva K, et al. Effects of the home learning environment and preschool center experience upon literacy and numeracy development in early primary school. Journal of Social Issues 2008;64(1):95-114.

32. Singh-Manoux A, Ferrie JE, Lynch JW, et al. The role of cognitive ability (intelligence) in explaining the association between socioeconomic position and health: evidence from the Whitehall II prospective cohort study. AmJEpidemiol 2005;161(9):831-39.

33. Coard B. How the West Indian Child is Made Educationally Subnormal in the British School System: The Scandal of the Black Child in Schools in Britain. 1971.

34. Strand S. The White British-Black Caribbean achievement gap: tests, tiers and teacher expectations. British Educational Research Journal 2011;38(1):75-101.

35. Sewell T. Black Masculinities and Schooling. How Black Boys Survive Modern Schooling: ERIC, 1997.

36. Kelly Y, Becares L, Nazroo J. Associations between maternal experiences of racism and early child health and development: findings from the UK Millennium Cohort Study. Journal of Epidemiology and Community Health 2012.

37. Coll CG, Crnic K, Lamberty G, et al. An Integrative Model for the Study of Developmental Competencies in Minority Children. Child Development 1996;67(5):1891-914.

38. Hill V. Through The Past Darkly: A Review of the British Ability Scales. Child and Adolescent Mental Health 2005;10(2):87-98.

39. National Center for Education Statistics. The Nation's Report Card: Trends in Academic Progress 2012 (NCES 2013-456). In: Institute of Education Sciences NAoEPN, ed. Washington, D.C., 2013.

40. Heath A, Ridge J. Social Mobility of Ethnic Minorities. Journal of Biosocial Science 1983;8:169-84. 